\title{
Congenital Absence of Permanent Canines: Report of Two Cases
}

\author{
Ann S. Smith* and Edward F. Harris \\ Department of Pediatric Dentistry, University of Tennessee, Memphis
}

\begin{abstract}
Congenital absence of permanent canines is a rare event, especially when syndromic cases are excluded. Our data suggest a population frequency of roughly 1 per 1,000 people. This report describes two contemporary cases with radiographically-confirmed bilateral absence of the maxillary canines. One is a case of simple hypodontia, where only the upper canines failed to develop (though the lateral incisors are under-
\end{abstract}

Most people develop all 32 permanent teeth, but the congenital absence of one or more of these teeth is not uncommon (Pindborg, 1970). Indeed, no tooth type is immune to failure-to-form, though some tooth types, notably the maxillary lateral incisor and second premolars are comparatively likely to experience congenital absence (Egermark-Eriksson and Lind, 1971; Mattheeuws et al., 2004). On the other hand, canines are renowned for their developmental stability; canines are the teeth least likely to be congenitally absent (Polder et al., 2004).

The population incidence of missing canines is hard to determine accurately because of variations among studies in selection criteria (e.g., whether syndromes are included), sampling fluctuations, and whether absence is verified radiographically (so failures of eruption can be distinguished from failure of formation).

The purpose of this report is to describe two contemporary clinical cases that are unusual in that both permanent canines are missing from one arch. There appears to be little effect of this rare form of hypodontia on the other teeth in one case, while the other case has additional missing teeth.

\section{Case Discovery}

One case (KP) was identified during a systematic review of orthodontic patients (Harris and Clark, 2008). These were "phenotypically normal" cases, where those with syndromes or other conditions known to enhance the risk of hypodontia had been culled. Exempted conditions included clefts of the lip and palate, hypohidrotic ectodermal dysplasia (Itin and Fistarol, 2004), and cases probably due to Pax9 or Msx1 (or similar major genes) that cause oligodontia size). The other case exhibits the additional absence of maxillary lateral incisors and second premolars. These cases add weight to prior findings that (A) the canine is the tooth type least likely not to form, (B) upper canines are more likely to be missing than mandibular canines, and $(C)$ the frequency is higher in females than males. Dental Anthropology 2008;21(2):54-59.

(Mostowska et al., 2003; Vieira, 2003; Larmour et al., 2005). The second case (LS) was encountered during routine treatment in a pediatric dental clinic and was referred to the authors for consultation.

Bothcases werefree of any identifiable developmental problem aside from the isolated hypodontia, though they were not tested genetically.

\section{Case KP}

This is a 15-7 year-old American black female (Fig. 1) who presented to the Department of Orthodontics with the major complaint that she disliked the space (ca. 5 $\mathrm{mm}$ ) between her maxillary central incisors. She herself was unaware that her canines were congenitally absent. Indeed, given the high incidence of impacted maxillary canines (e.g., Bishara, 1998; Richardson and Russell, 2000), their absence on initial visual inspection was not surprising; the orthodontist assumed at first that they were merely impacted. On radiographic examination, their absence was confirmed, though all 30 of the other permanent teeth were present. All four third molars appear to be eumorphic on X-ray.

Absence of the canines had led to lateral migration of the incisors, with interdental spacing, notably development of the midline diastema (Fig. 1). This recalls Moorrees' (1959) finding (and those of Baume (1950) and others) that the mesially-canted eruption paths of the canines promote consolidation of the

Correspondence to: Ann S. Smith, Department of Pediatric Dentistry, University of Tennessee, Memphis, Tennessee U.S.A. 38163

E-mail: ASMIT138@utmem.edu 


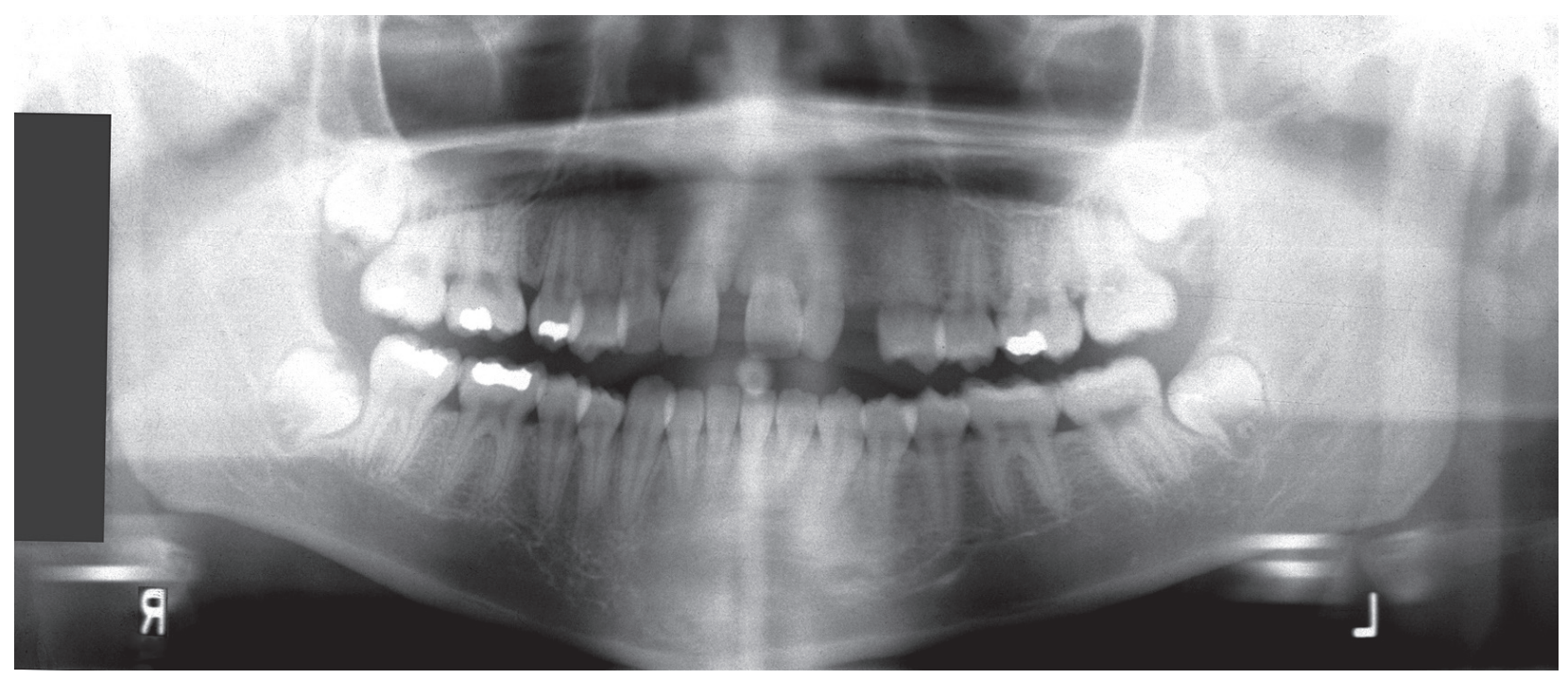

Fig. 1. Panoramic radiograph of case KP. All of the permanent teeth, including the 4 third molars, are mineralizing. Congenital absence is limited to the left and right maxillary canines.

incisors and, perhaps, lead to incisor crowding at this stage. It seems that, without the canines, incisors in the anterior segment remain spaced.

Overjet and overbite were both near-zero; indeed, there are small wear facets on some of the incisors where they occluded end-on. The maxillary left lateral incisor was in crossbite. The other obvious occlusal issue was that the mandibular right canine was displaced to the lingual while the adjacent first premolar was displaced to the buccal. One conjecture is that this premolar's eruption was diverted out of the arch form because of early loss of arch space that should have been retained by the deciduous canine and first molar in that quadrant (cf. Stefan, 2006).

Absence of the canines and asymmetric loss of primary teeth led to an asymmetric arch form (more obvious in the maxilla), where the buccal teeth on the right side are positioned farther mesially. This translated into a Class I buccal segment relationship on the left and an end-on Class II relationship on the right (cf. Harris and Corruccini, 2008).

The maxillary right deciduous canine had exfoliated some time ago, and mesial drift of the premolars and molars in that quadrant closed the space, so the first premolar was abutted against the lateral incisor. The deciduous canine on the left exfoliated quite recently, and a $9 \mathrm{~mm}$ space occurred behind the lateral incisor on that side when the pretreatment orthodontic records were taken.

Obvious orthodontic treatment options were either (1) to open the canine spaces for osseointegrated singletooth implants (e.g., Higuchi, 2000) or (2) to close the spaces, substituting (and recontouring) the first premolars to function as the canines. The latter course was chosen here, which required that the mandibular first premolars be extracted as part of treatment to achieve proper interdigitation between the jaws.

It is evident on inspection that, while all 30 teeth are present in this case (Figs. 1, 2), the maxillary lateral incisors are undersize: The right lateral incisor is small

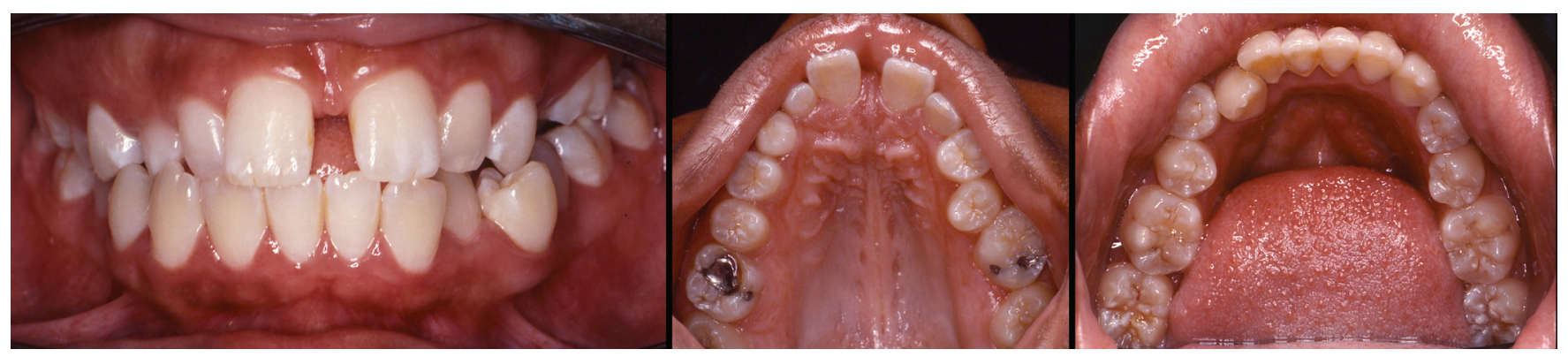

Fig. 2. Intraoral photographs of case KP. The missing maxillary canines are thought to contribute to the tapered arch form and the interdental spacing, particularly the maxillary midline diastema. The maxillary lateral incisors are undersize, notably in the subject's right quadrant. Premolar displacements (upper left and lower left quadrants) likely are due to early loss of primary teeth, though there is no solid dental history for this case. 


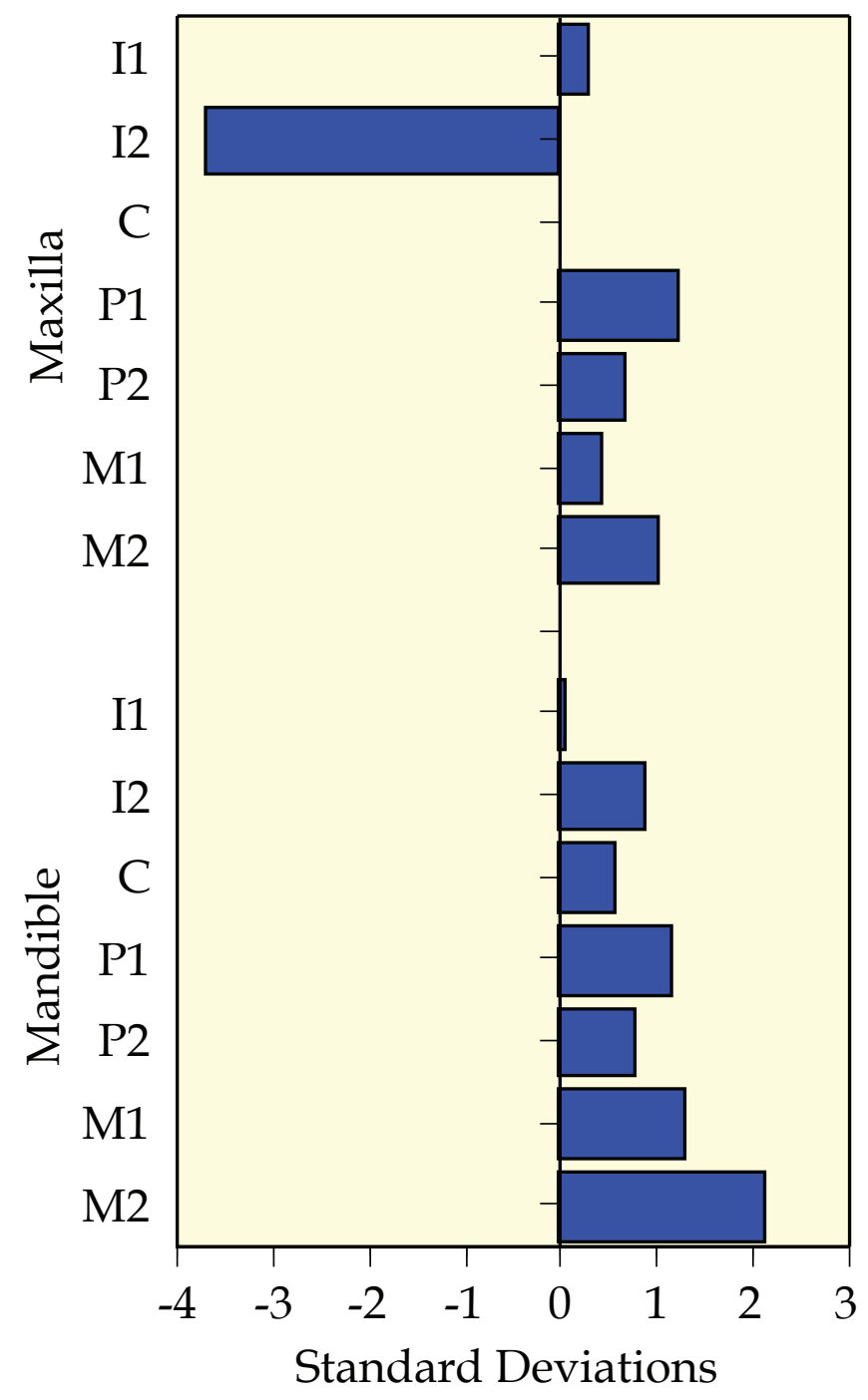

Fig. 3. Bar chart of the mesiodistal crown dimensions of case KP, expressed as z-scores. Aside from the small maxillary lateral incisors, all other tooth types are of at least normal size, suggesting that congenital absence of the canines is an anatomically localized, not a systemic problem, in this girl. The reference sample used here for comparison is the group of African American girls decscribed by Richardson and Malhotra (1976).

mesiodistally $(7.0 \mathrm{~mm})$ and the left lateral incisor is pegged with an essentially circular cross section (5.0 $\mathrm{mm}$ ). The mesiodistal crown dimensions of this case are graphed as z-scores (standard deviation units) in Fig. 3. Aside from the undersize maxillary lateral incisors just mentioned, none of the other tooth types is noteworthy; in fact, most dimensions are slightly above the average.

\section{Case LS}

The second case is a healthy American white female referred for consultation. The panoramic radiograph, taken at age 9-1 years (Fig. 4), reveals a mixed dentition with congenital absence of at least six permanent teeth (third molars not yet discernible). Specifically, there is bilateral absence of the permanent maxillary lateral incisors, canines, and second premolars. At this chronological age, third molar crypt formation often is evident (e.g., Rantanen, 1967), but not in this girl. History also revealed congenital absence of the primary maxillary lateral incisors. This recalls the developmental issue that, when a primary tooth is congenitally absent, most times the successor also will be absent because the permanent tooth bud branches off from its predecessor so absence of a primary tooth often foretells absence of its permanent replacement tooth (e.g., Avery, 1994).

Evaluation disclosed variability of developmental stages among the molar types. The development of the second maxillary right molar appears questionable (Fig. 4).

Studies suggest that tooth development is delayed in cases of hypodontia (Uslenghi et al. 2007). Using the Demirjian standards for tooth development (Demirjian et al., 1973) that we have adapted for the local population, this girl has a dental age of 5.9 years, which is delayed by $35 \%$ compared to her chronological age of 9.1 years.

Mesial drift of the maxillary first premolars into the sites of the canines is evident on the panoramic radiograph (Fig. 4). As well, there has been lateral drift of the central incisors that has established a prominent midline diastema. Lower anterior crowding also is evident. The malocclusion was treatment planned for serial extractions of the primary teeth and extraction of the mandibular first premolars. Age-appropriate maxillary anterior implants are included in the treatment plan to be placed when the bulk of the girl's facial growth is completed.

\section{Hypodontia}

The two cases described here are unusual in that congenital absence of permanent canines is rare, notably so in cases of simple hypodontia (in contrast to cases with oligodontia; Schalk-van der Weide, 1992). In a systematic review of adolescent cases with hypodontia (Harris and Clark, 2008), only 1 case of missing permanent canines was found in the sample of 1,600 , yielding a frequency of $0.06 \%$. Of note, this study excluded craniofacial syndromes and cases with oligodontia. This frequency is the same order of magnitude as reported by Dolder (1937) at $0.06 \%$ and by Bergström (1977) at $0.23 \%$. A recent study by Fukuta and coworkers (2004) identified 65 cases of congenitally missing permanent canines in their review of 35,927 dental patients $(0.18 \%)$, but this included cases of complex hypodontia. Large studies such as this suggest that canine hypodontia (A) is more common in females than males, (B) is more common in the maxilla than the mandible, and $(C)$ tends to be associated with hypodontia of other permanent teeth 


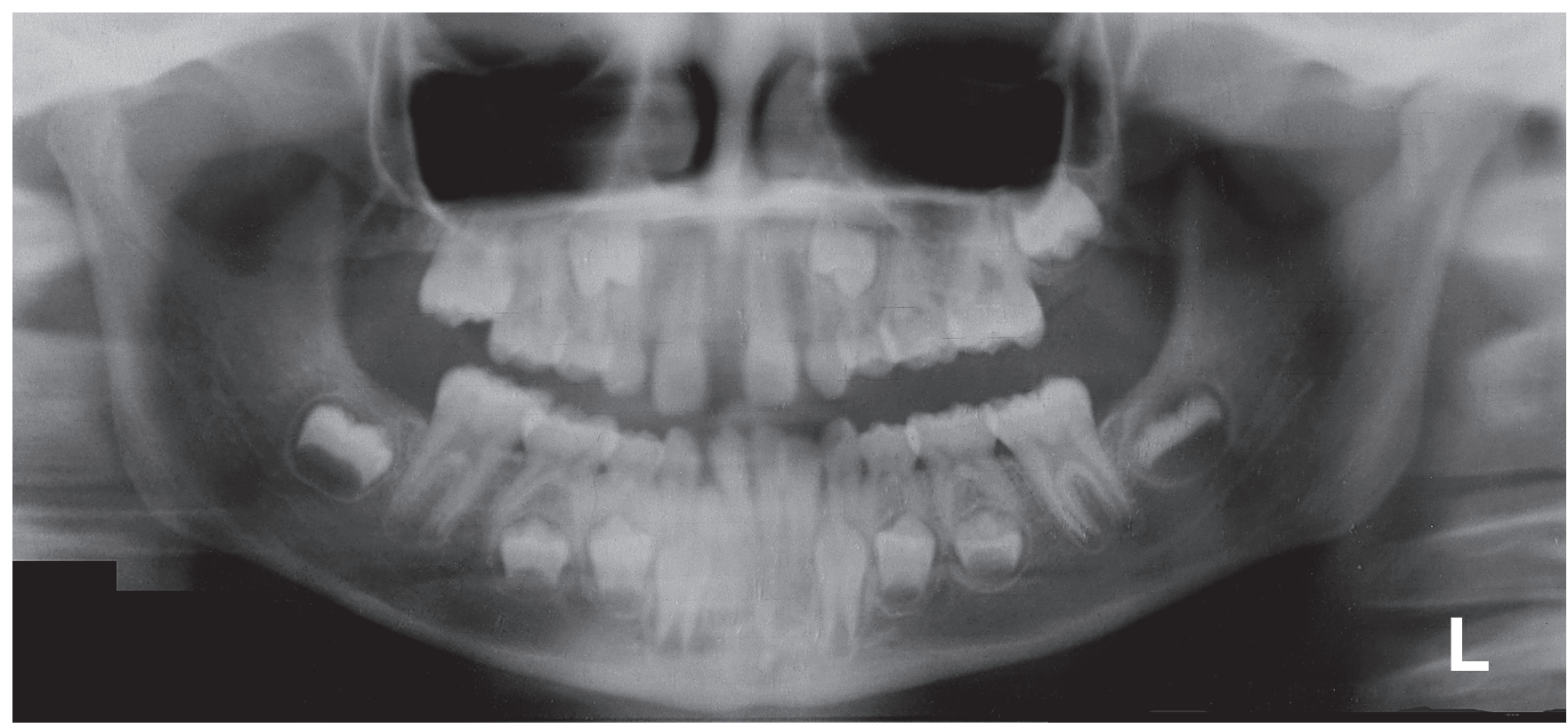

Fig. 4. Panoramic radiograph of case LS. Both maxillary canines are congenitally absent, as well as the lateral incisor and the second premolar in both maxillary quadrants. The other teeth are of normal size and morphology, though the girl is too young to know whether the third molars will develop. Notice, too, that it is uncertain whether the maxillary right second molar is forming; in any event it is appreciably delayed relative to the three other second molars. There is no third molar crypt formation in this girl (9-1 years). The developing maxillary first premolars are rotated (so both the lingual and buccal cusps are readily evident), but this is not particularly unusual.

(particularly maxillary lateral incisors, mandibular central incisors, and premolars).

Failure of a tooth's formation can occur at any of several steps during odontogenesis. Perhaps the most obvious situation is where the molecular signal from the ectoderm to the underlying mesoderm (dental lamina) fails to occur, so there is no initiation of bud formation, though the specific causes do not seem to be known. Formation also might cease when reciprocal signaling from the mesenchyme back to the ectoderm is lacking (e.g., Peters et al., 1998).

Formation also may cease during bud formation and, thus, before the initiation of mineralization (Harris, 2002). This has been documented in mice, rats, and rabbits. These animals do not possess lateral incisors (nor canines, nor premolars). However, careful histological study (Fitzgerald, 1973; Moss-Salentijn, 1978) discloses that lateral incisors begin formation, but development ceases in the bud stage, presumably because signaling to promote morphodifferentiation is lacking.

Causes of tooth suppression (or interrupton of formation) probably differ among species (e.g., Peterková et al., 2002). In the mouse, sprouty genes (antagonists of fibrobast growth factor (FGF) signaling) suppress tooth formation in the incisor-to-molar diastema by inhibiting Shh (sonic hedgehog) in this region. The mode of action seems to be that Shh expression in the diastema inhibits FGF signaling from the mesenchyme (Klein et al., 2006).
Of course, the mechanism in humans-let alone in the cases described here-may be unrelated to this scenario, but the point is that tooth agenesis has its basis in some failure of chemical signaling to promote development.

Influences from the environment also need to be considered as influencing the risk of hypodontia (where the "environment" interrupts normal biochemical signaling). The conjecture is that greater environmental stress on an individual during tooth initiation increases the risk of hypodontia. "Anthropological" cases of "stressed" populations (e.g., Bailit et al., 1970) do not provide strong evidence of this because the level of stress is merely conjectured post hoc. We suggest that a more telling situation occurs in children treated for acute lymphocytic leukemia (e.g., Kaste et al., 1997). These children are otherwise normal, but have acute onset of leukemia that has to be treated aggressively with chemotherapy and/or cranial irradiation (Pui, 1999). Hypodontia consequent to irradiation is predictable because the formative cells are killed (Kaste and Hopkins, 1994). Notably, children treated with chemotherapy alone also have substantially greater frequencies of hypodontia (Weathersby, 2006). We interpret these cases as dramatic situations in which the environmental stressors (chemotherapy) can halt tooth development.

Harris and Hullings (1990) suggested a similar scenario for children with cleft of the lip and palate. 
Hypodontia is appreciably higher in children with clefts (Böhn, 1963; Ranta, 1983, 1986), and Harris speculated that this is consequent to the cleft, with failure to thrive, recurrent middle ear and upper respiratory infections, the stress of repeated surgeries, and the like. The scenariogreater hypodontia in response to greater environmental stress - is still attractive, but it is considerably more speculative now that there is greater appreciation of a genetic basis for isolated (nonsyndromic) clefts (e.g., Peters et al., 19981; Satokata and Maas, 1994; Vieira, 2003; Zucchero et al., 2004).

Mutant forms of Pax9, Msx1, and Axin2, among other genes, have been documented to promote hypodontia (Cobourne, 2007; Matalova et al., 2008). These genes, however, have fairly dramatic effects-typically resulting in the congenital absence of multiple teeth. In part, this is because it has been technically easier to identify the familial effects of genes with dramatic effects on the phenotype. One supposes that other genes, with less severe and, thus, more common effects - such as the absence of single teeth ("simple hypodontia") will be identified with more refined studies in the future.

\section{The Canine}

Sadly, we offer no explanation for the symmetric congenital absence of permanent canines in the two cases described here. Although there is only one canine per quadrant, the canine rarely is absent, and its morphogenetic effects on adjacent teeth in terms of cingular morphology (Turner, 1969; Scott, 1977) and the extent of sexual dimorphism (Garn et al., 1977) are well documented.

The literature suggests that there is some familial aggregation of canine absence (e.g., Postello, 1984; Huggare, 1984)-which might imply a genetic basis for some cases-but such case studies probably are over-reported since they are noteworthy. Alternatively, very few studies have explicitly studied hypodontia in sibships (as opposed to samples of biologically unrelated individuals), so an unbiased estimate of recurrence in families is unavailable.

\section{OVERVIEW}

Two cases of congenital absence of permanent maxillary canines are described. In one case, these are the only teeth that failed to form; in the other, maxillary lateral incisors and second premolars also were absent. Etiology of this rare condition remains speculative.

\section{REFERENCES CITED}

Avery JK, editor. 1994. Oral development and histolog, 2nd ed. New York: Thieme Medical Publishers, Inc.

Bailit HL, Workman PL, Niswander JD, MacLean CJ. 1970. Dental asymmetry as an indicator of genetic and environmental conditions in human populations. Hum Biol 42:626-638.
Baume LJ. 1950. Physiological tooth migration and its significance for the development of occlusion. II. The biogenesis of accessional dentition. J Dent Res 29:331-337.

Bergström K. 1977. An orthopantomographic study of hypodontia, supernumeraries and other anomalies in school children between the ages of 8-9 years. An epidemiological study. Swed Dent J 1:145-157.

Bishara SE. 1998. Clinical management of impacted maxillary canines. Semin Orthod 4:87-98.

Böhn A. 1963. Dental anomalies in harelip and cleft palate. Acta Odontol Scand Suppl 38:1-109.

Cobourne MT. 2007. Familial human hypodontia - is it all in the genes? Br Dent J 203:203-208.

Demirjian A, Goldstein H, Tanner JM. 1973. A new system of dental age assessment. Hum Biol 45:211227.

Dolder E. 1937. Deficient dentition: statistical survey. Dent Record 57:142-143.

Egermark-Eriksson I, Lind V. 1971. Congenital numerical variation in the permanent dentition. D. Sex distribution of hypodontia and hyperodontia. Odontol Revy 22:309-315.

Fitzgerald LR. 1973. Deciduous incisor teeth of the mouse (Mus musculus). Arch Oral Biol 18:381-389.

Fukuta Y, Totsuka M, Takeda Y, Yamamoto H. 2004. Congenital absence of the permanent canines: a clinico-statistical study. J Oral Sci 46:247-252.

Garn SM. 1977. Genetics of tooth development. In: McNamara JA, editor. The biology of occlusal development. Ann Arbor, MI: Craniofacial Growth Series, p. 61-88.

Harris EF. 2002. Dental development and anomalies in craniosynostosis and facial clefting. In: Mooney MP, Siegel MI, editors. Understanding craniofacial anomalies: the etiopathogenesis of craniosynostosis and facial clefting. New York: John Wiley-Liss, p 425467.

Harris EF, Clark LL. 2008. An epidemiological study of hyperdontia in American blacks and whites. Angle Orthod 78:460-465.

Harris EF, Corruccini RS. 2008. Quantification of dental occlusal variation: a review of methods. Dental Anthropology 21:1-11.

Harris EF, Hullings JG.1990. Delayed dental development in children with isolated cleft lip and palate. Arch Oral Biol 35:469-473.

Higuchi KW. 2000. Orthodontic applications of osseointegrated implants. Chicago: Quintessence Publishing Company, Inc.

Huggare J. 1984. Congenital aplasia of four permanent cuspids: a case report. Proc Finn Dent Soc 80:257259

Itin PH, Fistarol SK. 2004. Ectodermal dysplasias. Am J Med Genet C Semin Med Genet 131C:45-51.

Kaste SC, Hopkins KP. 1994. Micrognathia after radiation 
therapy for childhood facial tumors. Oral Surg Oral Med Oral Path 77:1:95-99.

Kaste SC, Hopkins KP, Jones D, Crom D, Greenwald CA, Santana VM. 1997. Dental Abnormalities in children treated for acute lymphoblastic leukemia. Leukemia 11:792-796.

Klein OD, Minowada G, Peterkova R, Kangas A, Yu BD, Lesot H, Peterka M, Jernvall J, Martin GR. 2006. Sprouty genes control diastema tooth development via bidirectional antagonism of epithelialmesenchymal FGF signaling. Dev Cell 11:181-190.

Larmour CJ, Mossey PA, Thind BS, Forgie AH, Stirrups DR. 2005. Hypodontia-a retrospective review of prevalence and etiology. Part I. Quintessence Int 36:263-270.

Matalova E, Fleischmannova J, Sharpe PT, Tucker AS. 2008. Tooth agenesis: from molecular genetics to molecular dentistry. J Dent Res 87:617-623.

Mattheeuws N, Dermaut L, Martens G. 2004. Has hypodontia increased in Caucasians during the 20th century? A meta-analysis. Eur J Orthod 26:99-103.

Moorrees CFA. 1959. The dentition of the growing child. Cambridge: Harvard University Press.

Moss-Salentijn L. 1978. Vestigial teeth in the rabbit, rat and mouse; their relationship to the problem of lacteal dentitions. In: Butler PM, Joysey KA, editors. Development, function and evolution of teeth. London: Academic Press Inc, p 13-29.

Mostowska A, Kobielak A, Trzeciak WH. 2003. Molecular basis of non-syndromic tooth agenesis: mutations of MSX1 and PAX9 reflect their role in patterning human dentition. Eur J Oral Sci 111:365-370.

Peterková R, Peterka M, Viriot L, Lesot H. 2002. Development of the vestigial tooth primordia as part of mouse odontogenesis. Connect Tissue Res 43:120128.

Peters H, Neubüser A, Kratochwil K, Balling R. 1998. Pax9-deficient mice lack pharyngeal pouch derivatives and teeth and exhibit craniofacial and limb abnormalities. Genes Dev 12:2735-2747.

Pindborg JJ. 1970. Pathology of the dental hard tissues. San Francisco: WB Saunders Company.

Polder BJ, Van't Hof MA, Van der Linden FP, KuijpersJagtman AM. 2004. A meta-analysis of the prevalence of dental agenesis of permanent teeth. Community Dent Oral Epidemiol 32:217-226.
Postello DR. 1984. Congenitally missing maxillary canines: a report of two cases. Ont Dent 61:10-12.

Pui CH. 1999. Acute lymphoblastic leukemia. In: GR Lee. Wintrobe's clinical hematology. Baltimore: Williams \& Wilkins, p 1141-1153.

Ranta R. 1983. Hypodontia and delayed development of the second premolars in cleft palate children. Eur J Orthod 5:145-148.

Ranta R. 1986. A review of tooth formation in children with cleft lip/palate. Am J Orthod Dentofac Orthop 90:11-18.

Rantanen AV. 1967. The age of eruption of the third molar teeth. Acta Odont Scand 25:1-86.

Richardson G, Russell KA. 2000. A review of impacted permanent maxillary cuspids-diagnosis and prevention. J Can Dent Assoc 66:497-501.

Richardson ER, Malhotra SK. 1975. Mesiodistal crown dimension of the permanent dentition of American Negroes. Am J Orthod 1975;68:157-164.

Satokata I, Maas R. 1994. Msx1 deficient mice exhibit cleft palate and abnormalities of craniofacial and tooth development. Nat Genet 6:348-356.

Schalk-van der Weide Y. 1992. Oligodontia: a clinical, radiographic and genetic evaluation. Utrecht: Rijksuniversiteit Utrecht.

Scott GR. 1977. Lingual tubercles and the maxillary incisor-canine field. J Dent Res 56:1192.

Stefan VH. 2006. Rotation of the maxillary premolars: evidence in support of premolar morphogenetic field. Dental Anthropology 70:19:70-82.

Turner CG 2nd. 1969. Directionality in the canine field model. J Dent Res 48:1310.

Uslenghi S, Liversidge HM, Wong FS. 2006. A radiographic study of tooth development in hypodontia. Arch Oral Biol 51:129-133.

Vieira AR. 2003. Oral clefts and syndromic forms of tooth agenesis as models for genetics of isolated tooth agenesis. J Dent Res 82:162-165.

Weathersby MG. 2006. Dental maturation in children treated for acute lymphoblastic leukemia. M.D.S. Thesis, University of Tennessee, Memphis.

Zucchero TM, Cooper ME, Maher BS, Daack-Hirsch S, Nepomuceno B, Ribeiro L, et al. 2004. Interferon regulatory factor 6 (IRF6) gene variants and the risk of isolated cleft lip and palate. N Engl J Med 351:769780 . 